\title{
Subtropical South American Hailstorm Characteristics and Environments
}

\author{
ZACHARY S. BRUICK AND KRISTEN L. RASMUSSEN \\ Department of Atmospheric Science, Colorado State University, Fort Collins, Colorado \\ DANIEL J. CECIL \\ NASA Marshall Space Flight Center, Huntsville, Alabama
}

(Manuscript received 14 January 2019, in final form 21 August 2019)

\begin{abstract}
Hailstorms in subtropical South America are known to be some of the most frequent anywhere in the world, causing significant damage to the local agricultural economy every year. Convection in this region tends to be orographically forced, with moisture supplied from the Amazon rain forest by the South American low-level jet. Previous climatologies of hailstorms in this region have been limited to localized and sparse observational networks. Because of the lack of sufficient ground-based radar coverage, objective radar-derived hail climatologies have also not been produced for this region. As a result, this study uses a 16-yr dataset of TRMM Precipitation Radar and Microwave Imager observations to identify possible hailstorms remotely, using 37-GHz brightness temperature as a hail proxy. By combining satellite instruments and ERA-Interim reanalysis data, this study produces the first objective study of hailstorms in this region. Hailstorms in subtropical South America have an extended diurnal cycle, often occurring in the overnight hours. In addition, they tend to be multicellular in nature, rather than discrete. High-probability hailstorms $(\geq 50 \%$ probability of containing hail) tend to be deeper by $1-2 \mathrm{~km}$ and horizontally larger by greater than $15000 \mathrm{~km}^{2}$ than storms having a low probability of containing hail ( $<25 \%$ probability of containing hail). Hailstorms are supported synoptically by strong upper- and lower-level jets, anomalously warm and moist low levels, and enhanced instability. The findings of this study will support the forecasting of these severe storms and mitigation of their damage within this region.
\end{abstract}

\section{Introduction}

Hail in subtropical South America can be very large (Rasmussen et al. 2014) and frequent (10-30 storms per year in central Argentina; Cecil and Blankenship 2012), and it causes significant impacts to property and the agricultural economy in this region. Hail has been studied for more than five decades, yet relatively little is known about the storms that produce hail or the environments that support hail-producing storms in subtropical South America. Hail research in the region goes back to the 1960s, when hail mitigation experiments began near Mendoza, Argentina (Grandoso and Iribarne 1963). Hail observations were extremely limited at this time, but some frequency of hail was noted near the Atlantic coast and the Andes Mountains (Frisby and Sansom 1967; Williams 1973). More recent

\footnotetext{
Corresponding author: Zachary S. Bruick, zbruick@rams.colostate. edu
}

mitigation work has continued in the Mendoza area to reduce hail risk to wineries (Makitov 1999) and to study the time series of hail events (Prieto et al. 1999). Large hail $(>2 \mathrm{~cm})$ was found to cause $80 \%$ of the agricultural damages in the Mendoza region through only 2-3 events annually (Pérez and Puliafito 2006). An in-depth study of hailpad observations was undertaken by Sánchez et al. (2009), which compared the hailpad climatologies of Mendoza with those of regions in France and Spain. This study found that the network in Argentina has a greater frequency of large hailstones than those in Europe. Other recent hail research in South America includes the analyses of hailpad observations in Colombia (Arias and Ramiro 2010) and the national hail-report database in Brazil (Martins et al. 2017).

The most thorough report-based hail climatology for subtropical South America used weather station observations of hail to produce an interpolated gridded hail frequency (Mezher et al. 2012). This study highlighted two main areas of frequent hail: 1) Mendoza, extending 
east toward Córdoba and the central plains of Argentina, and 2) Patagonia, Argentina (see Fig. 1 for geographical references). This southern region of hail activity may be a result of graupel being counted as hail in this colder region of the continent, because the hail frequency in this region is relatively higher in winter and spring than in other regions of Argentina. Mezher et al. (2012) also found that hailstorms tend to occur when there are warm temperature anomalies near the surface and cold anomalies in the upper atmosphere, leading to the creation of an unstable atmosphere. While this study produced a national hail climatology over an extended time period, it was limited to surface station observations, which are relatively sparse across the region within Argentina and must be manually recorded by an observer. Ground-based radar-derived hail climatologies, such as those conducted in the United States (e.g., Počakal et al. 2009; Cintineo et al. 2012), are unable to be produced in subtropical South America because of the very recent installation of ground-based radar networks in Argentina. With time, this will be a promising avenue to explore hail within this region, but currently the data record is not extensive enough for a thorough analysis.

As a result, the most comprehensive way to examine the climatology of hail in subtropical South America and compare these results to other parts of the world is to use passive microwave satellite observations of ice hydrometeors. These measurements have been shown to be well-calibrated to large hail reports ( 1 in. or greater diameter; 1 in. $=2.54 \mathrm{~cm}$ ) within the United States (Cecil 2009), which has allowed their use in producing global climatologies of hailstorms and intense convection (Cecil and Blankenship 2012; Ferraro et al. 2015; Ni et al. 2016; Mroz et al. 2017; Bang and Cecil 2019). It is important to note that these methods are limited in the tropics and thus the inferred frequency should be adjusted to lower values, as deep layers of large graupel can produce similar signatures as hail (Cecil and Blankenship 2012; Ferraro et al. 2015). However, the subtropical region of South America is more similar to the subtropical United States where the climatologies were trained than to the equatorial tropical regions such as the Congo rain forest in Africa; therefore no adjustment is required (Cecil and Blankenship 2012). These satellite-based hail studies found intense convection with likely hail production, and specifically maxima in hail frequency, in the lee of major mountain ranges that is consistent with spaceborne radar-based climatologies of deep convection (Zipser et al. 2006; Houze et al. 2015). These findings also correspond well to recent observational work in Canada (Smith and Yau 1993; Etkin and Brun 2001), Croatia (Počakal et al. 2009), China (Zhang et al. 2008; Li et al.

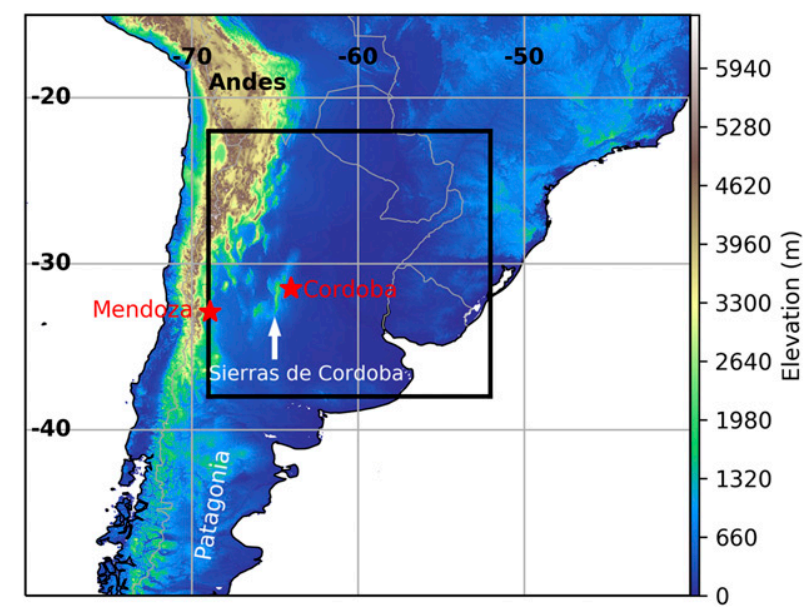

FIG. 1. Southern South America with topography shaded and the study area outlined.

2018), and Argentina (Mezher et al. 2012). However, the frequencies of hail within these different regions show a large degree of variability. In comparing the foothills of the Rockies with the foothills of the Andes, it is seen that there is an order-of-magnitude increase in the frequency of large hail in the subtropical South American region (Cecil and Blankenship 2012). The reason for this difference between hail frequencies in close proximity to major mountain ranges is not well understood.

Meanwhile, examination of extreme convection using the Tropical Rainfall Measuring Mission (TRMM) satellite's Precipitation Radar (PR) showed that subtropical South America has some of the most extreme deep convection anywhere in the world (Zipser et al. 2006; Houze et al. 2015). This convection tends to be orographically favored, with warm and moist air supplied by the South American low-level jet (SALLJ) from the Amazon region and convective inhibition through mechanical subsidence in the lee of the Andes (Rasmussen and Houze 2011, 2016). These storms remain close to the terrain, backbuilding over time (Rasmussen et al. 2014). Even as stratiform precipitation develops downstream, deep convection often remains tied to the terrain, where constant orographic lift and moisture convergence enables maintenance of strong convection. Additionally, these extreme storms have been linked with the production of severe hazards, including hail, tornadoes, and flash flooding. However, the lack of an extensive storm report database in this region prevents an in-depth collocation of the TRMM PR dataset with storm reports.

Therefore, this study seeks to combine TRMM PR and radiometer measurements to examine the diurnal and annual cycles and characteristics of likely hailstorms, and use ERA-Interim reanalysis data to 
identify the synoptic environments that support hailstorms in subtropical South America, as such data synthesis has been shown to be useful for objective analysis of hailstorms and their synoptic environments (e.g., Punge et al. 2017; Bedka et al. 2018). The results of this study will improve the understanding of how, why, and when hailstorms form and what characteristics may differentiate them from convection that does not produce hail. Through this analysis, a more comprehensive understanding of the climatology of hail and hail-producing environments will be presented. The results from this study will provide context for the results of the Remote Sensing of Electrification, Lightning, and Mesoscale/Microscale Processes with Adaptive Ground Observations (RELAMPAGO) field campaign (1 November-18 December 2018; https:// www.eol.ucar.edu/field_projects/relampago) and the Cloud, Aerosol, and Complex Terrain Interactions (CACTI) field campaign (1 October 2018-30 April 2019; https://www.arm.gov/research/campaigns/amf2018cacti). This study will contribute to a better global understanding of hailstorms to help to improve forecasting and diagnosis of hailstorms in subtropical South America.

\section{Method}

Because of the lack of a hail-report database in subtropical South America, satellite measurements of ice scattering serve as sufficient proxies for analyzing convection that may support the production of hail (Cecil 2009; Cecil and Blankenship 2012). Using the methods established in Cecil and Blankenship (2012), 16 years of data (1998-2013) from the TRMM satellite were used. The PR and TRMM Microwave Imager (TMI) were utilized to identify convection and determine the probability that it contains hail. The TRMM satellite orbited the tropics between $35^{\circ} \mathrm{N}$ and $35^{\circ} \mathrm{S}$ from 1997 to 2014 (Kummerow et al. 1998). With this precessing orbit, TRMM conducted 3-4 overpasses per day within the study region, with overpass times varying with each orbit. While this could cause under- or oversampling of individual storm complexes, given the length of this study, these sampling artifacts should have minimal impact on the aggregated observations. TRMM PR had a resolution of $4-5 \mathrm{~km}$ horizontally and $250 \mathrm{~m}$ vertically, and the TMI had a resolution of $16 \mathrm{~km}$ by $9.7 \mathrm{~km}$ for the $37-\mathrm{GHz}$ channel (Kummerow et al. 1998, 2000). The 37-GHz channel is the best frequency on the TMI to discriminate whether convection is likely to produce hail (Cecil 2009). Lower frequencies have more sensitivity to large particles but sacrifice horizontal resolution. It is also important to note that this approach to hail identification is unable to distinguish hail size, because the satellite is only able to detect the volume of large ice particles within a storm.

TMI deciphers whether a storm is likely to contain hail, but it does not provide direct information about the three-dimensional characteristics of the storm. As a result, collocated TRMM PR data are used to provide details about hailstorm structure. Two TRMM data products are used in this study:

1) $2 \mathrm{~A} 23$ (rain characteristics; Awaka et al. 1997), in which precipitation is separated into the three categories of convective, stratiform, and other, and

2) 2 A25 (rainfall rate and profile; Iguchi et al. 2000), which contains the three-dimensional attenuationcorrected reflectivity data.

To focus this study on hail-producing convection in subtropical South America, a study area was defined that includes the primary region of intense convection and satellite-derived climatological hail maximum (Fig. 1; Cecil and Blankenship 2012; Rasmussen et al. 2014, 2016). The study area includes the Andean foothills and Sierras de Córdoba (SDC), which are hypothesized to be an orographic trigger for convective initiation (Rasmussen and Houze 2011, 2016) because of the impingement of the SALLJ on the topography. The orographic forcing helps to overcome any mechanical capping produced by subsiding upper-level air in the lee of the Andes. Additionally, the SDC and the plains immediately to their east were the focus of the RELAMPAGO and CACTI field campaigns.

To understand the life cycle of intense convection, the TRMM PR data were separated into three categories, including deep, deep and wide, and wide convective cores (DCCs, DWCCs, and WCCs, respectively) following the method established by Houze et al. (2007) and Romatschke and Houze (2011). DCCs are defined as convection that has a contiguous three-dimensional $40-\mathrm{dB} Z$ echo above $10 \mathrm{~km}$, WCCs are storms that have a contiguous $40-\mathrm{dBZ}$ echo over $1000 \mathrm{~km}^{2}$, and DWCCs are convection that meet the criteria to be both DCCs and WCCs. DWCCs are a subset of DCCs and WCCs, but in this study they are treated as an exclusive category, such that there is no overlap in data among the three storm types. DCCs and DWCCs represent the most intense deep convection, and the DWCCs and WCCs are indicative of mesoscale convective systems, which are large, well-organized, mature convective storms (Houze 2004). This method has been used in many previous studies on convective storm characteristics around the world (Rasmussen et al. 2014, 2016; Rasmussen and Houze 2011, 2016; Zuluaga and Houze 2015).

The 37-GHz polarization-corrected brightness temperatures (PCT; Cecil and Chronis 2018) from TMI are 
TABLE 1. The number of storms identified by the TRMM PR and TMI during 1998-2013 within the study area by storm type and hail probability.

\begin{tabular}{lrrrr}
\hline \hline & DCC & DWCC & WCC & Total \\
\hline $\begin{array}{l}\text { High-probability hailstorms } \\
\quad(>50 \% \text { probability of hail })\end{array}$ & 167 & 364 & 79 & 610 \\
$\begin{array}{l}\text { Medium-probability hailstorms } \\
\quad(25 \% \leq x \leq 50 \%\end{array}$ & 215 & 425 & 266 & 906 \\
$\quad \begin{array}{l}\text { probability of hail }) \\
\quad \begin{array}{l}\text { Null-case hailstorms } \\
\quad<25 \% \text { probability of hail })\end{array}\end{array}$ & 919 & 399 & 2546 & 3864 \\
$\quad$ Total & 1301 & 1188 & 2891 & \\
\hline
\end{tabular}

analyzed to assign probabilities that DCCs, DWCCs, and WCCs contained hail. Correcting the brightness temperatures based on the differences between the polarized channels allows for discrimination between surface water features and ice scattering within convection. The probability that a storm contained large hail is based on Cecil and Blankenship (2012), who computed calibrated probabilities using reports of hail of 1-in. $(2.54 \mathrm{~cm})$ diameter or larger in the United States. If the storm had a $37-\mathrm{GHz}$ PCT greater than $200 \mathrm{~K}$, it was found to have a low probability (less than $25 \%$ ) of hail and was designated as a null case in this study. Storms with 37-GHz PCTs between 176 and $200 \mathrm{~K}$ were considered to have a medium probability of hail; those thresholds correspond to between $25 \%$ and $50 \%$ likelihood of large hail (at least 1-in. diameter, or $2.54 \mathrm{~cm}$ ) being reported in the United States. Storms with $37-\mathrm{GHz}$ PCT below $176 \mathrm{~K}$ have a high probability $(>50 \%)$ of producing large hail. These classifications based on 37-GHz PCT allowed for investigation into differences between storms with different probabilities of containing hail. To analyze the statistical significance of differences in storm characteristics between probabilitybinned storms, two-sided $t$ tests were employed, because normal distributions can be assumed through the large number of storms analyzed and the central limit theorem.

Synoptic environments for each storm were analyzed with ERA-Interim reanalysis data (Dee et al. 2011). All maps use 1800 UTC, or 1500 local time (LT) in Argentina, for the composite, which was composed of days on which storms were observed after 1200 UTC or the day prior if the storms were observed before 1200 UTC. All days analyzed in this study had at least one storm occur between 1800 and 0000 UTC. This method best represents the initiating environment for these storms, because they typically form in the afternoon hours (Rasmussen et al. 2014). In addition, this time best represents the time of peak heating and instability in this region and is therefore the most

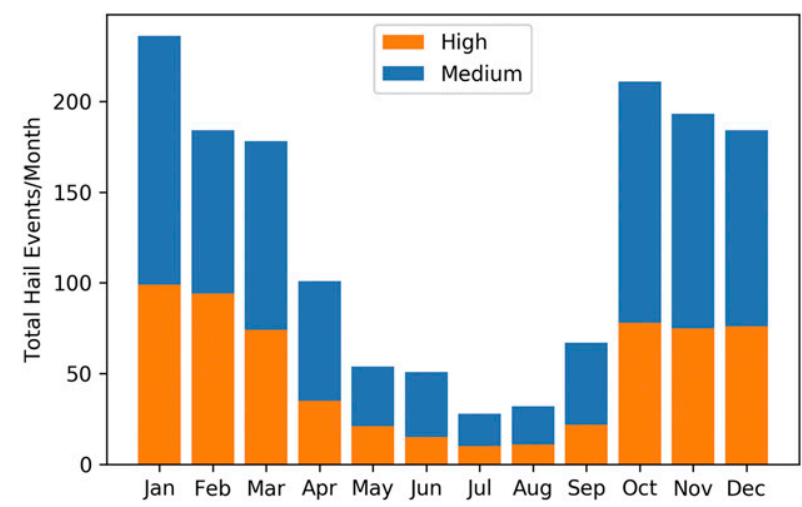

FIG. 2. The annual cycle of hailstorms within the study area as a stacked bar graph of upper-threshold and lower-threshold hailstorms.

representative time for synoptic conditions for intense convection given the 6-hourly time resolution of ERAInterim (Punge et al. 2017; Bedka et al. 2018). Days were binned by hail probability category (high, medium, or null) based upon the maximum hail probability that occurred during each day. Parameters analyzed within this study were retrieved directly from the ERA-Interim data.

\section{Results}

\section{a. Annual and diurnal cycles}

During the 16-yr observational period, a large number of storms were captured by the TRMM satellite (Table 1). DWCC storms contained the greatest percentage of potential hailstorms $(66.4 \%$, or 789 of 1188 storms), $29.4 \%$ of DCCs (382 of 1301) were potential hailstorms, and only $11.9 \%$ of WCCs (345 of 2891) were classified as potential hailstorms. The annual cycle of hailstorms in this region is similar to that in the United States (Allen and Tippett 2015), with the maximum frequency of hail occurring during the austral warm season (October-March; Fig. 2). Hailstorm activity begins to increase during September, reaches a fairly steady frequency from October through March, and the frequency decreases in April with reduced hail activity during the austral winter. These results match well with the annual cycle found by Mezher et al. (2012) in their E and H regions, which cover central and northwestern Argentina, respectively.

An examination of the diurnal cycle of hailstorms demonstrates the unique nature of these storms in subtropical South America (Fig. 3). Hailstorm activity begins to increase early in the afternoon (1700 UTC; 1400 LT) and continues through the next morning. This diurnal cycle is significantly extended into the nocturnal hours relative to what is observed in the United States, 


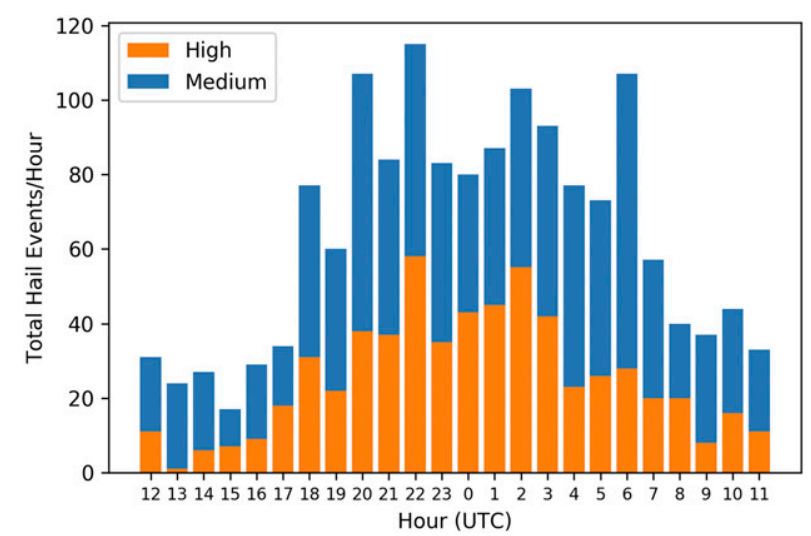

FIG. 3. The diurnal cycle of hailstorms within the study area as a stacked bar graph of upper-threshold and lower-threshold hailstorms.

where hail is infrequent after midnight (Allen and Tippett 2015). Cecil and Blankenship (2012) noted a broad peak between 1500 and 0000 LT for subtropical South America, with a slow decline in activity through the morning hours. This contrasted with sharp declines after 2100 LT for all other regions with high hail frequencies in their study - the United States, Central Africa, Pakistan, and Bangladesh. The high-probability storms in Fig. 3 have their maximum frequency from 2000 to 0300 UTC (1700-0000 LT). For medium-probability events, the period of maximum frequency extends through 0600 UTC (0300 LT). This enhanced frequency of hail during the overnight hours is a unique feature of subtropical South America, which has also been anecdotally observed via surface station and social media reports (Piersante 2017). Additionally, Martins et al. (2017) also noted this extended diurnal cycle of hail in southern Brazil, with a secondary maximum in hail frequency occurring between 0400 and 0600 LT.

Breaking the diurnal cycle down by storm type, highprobability, hail-producing DCCs and DWCCs have similar diurnal cycles, with their primary frequency peak during the late afternoon and evening hours (Fig. 4a). High-probability WCC hailstorms tend to form later in the day, as storms grow upscale, so the WCC diurnal cycle is delayed, with the maximum frequency between 2200 and 0400 UTC. Without regard for hail, the diurnal cycle for WCCs is similar to that found in the United States (Haberlie and Ashley 2019). The mediumprobability cases for all three types of extreme convection follow a diurnal pattern that is similar to that of their high-probability counterparts during the day and early evening through 0200 UTC, although the DCCs are more favored than the other storm types during this time period (Fig. 4b). However, after that time, mediumprobability storms have a second peak in frequency while the high-probability cases diminish. While this was seen earlier in Fig. 3, it is noteworthy that this overnight frequency maximum is a product of increases in the frequency of medium-probability hailstorms of all extreme storm types, but especially of WCCs and DWCCs. This overnight maximum aligns with the 0600 UTC peak in heavy rainfall for this region, shown by Matsudo and Salio (2011). A picture emerges of storm severity peaking in the evening and early nighttime hours, with storm coverage and rainfall peaking later in the overnight. Consistent with this, Matsudo and Salio (2011) showed a peak in extreme wind gusts around 2100 UTC, a gradual decline of wind gusts during the night, and then the peak of heavy rainfall at 0600 UTC.

The nocturnal maxima of hailstorms in subtropical South America can also be seen in a spatial dimension using Hovmöller diagrams. Storms were composited for these diagrams if they occurred between $28^{\circ}$ and $36^{\circ} \mathrm{S}$, to match the method of Rasmussen et al. (2014) and to identify the unique backbuilding component of convection in this region. It is important to note that TRMM does not capture the life cycle of individual storms given its orbit, but by compositing all of the

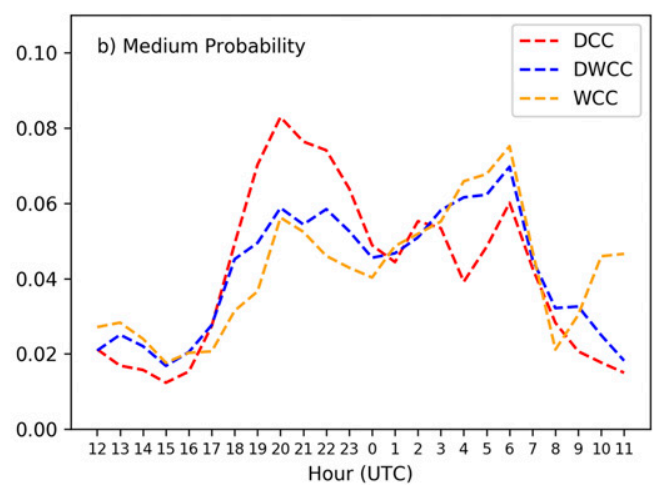

FIG. 4. The diurnal cycle of hailstorms within the study area separated by hail probability and storm type: (a) higher-probability hailstorms and (b) medium-probability hailstorms. 

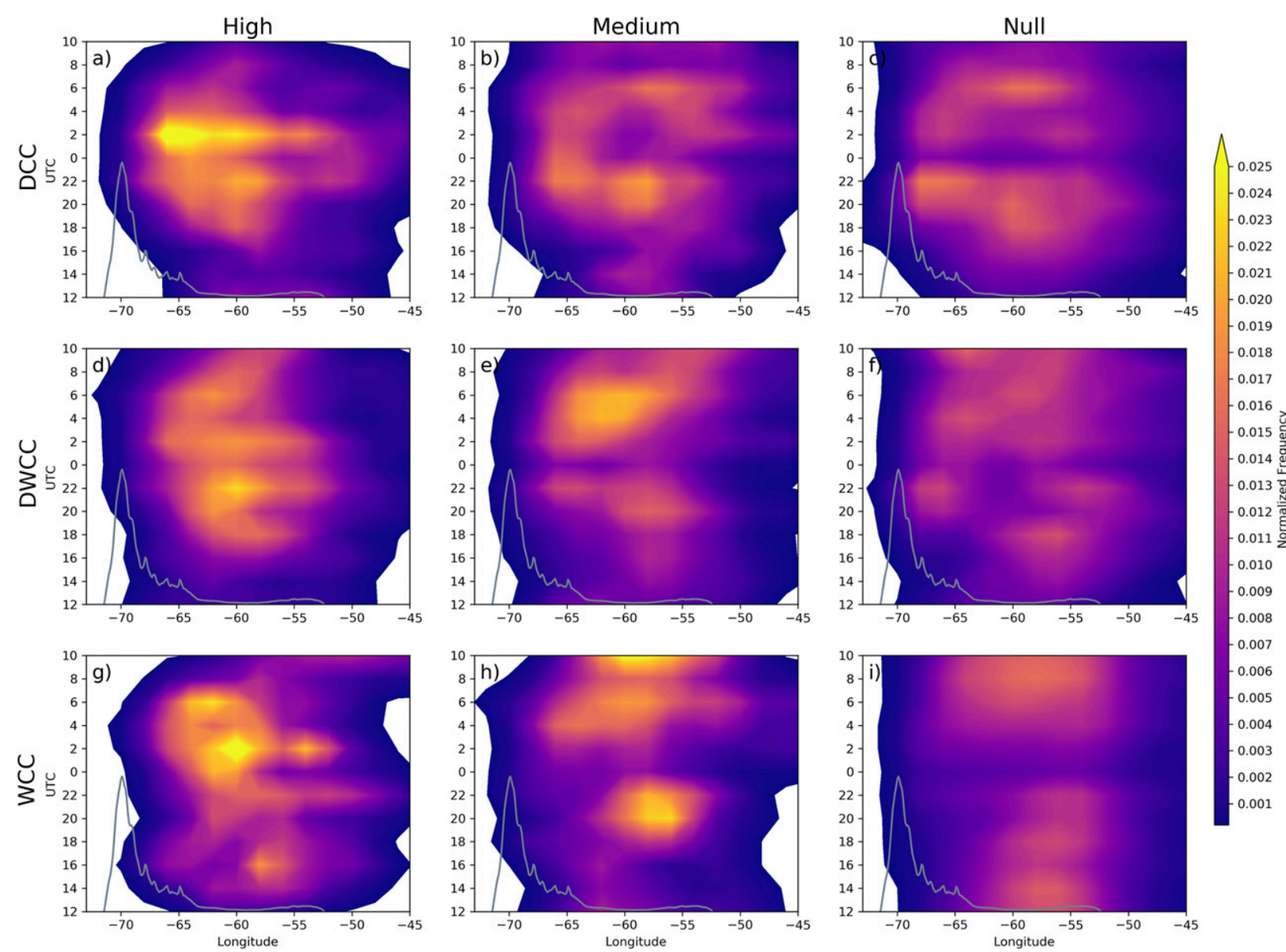

FIG. 5. Hovmöller diagrams of storm frequency between $28^{\circ}$ and $36^{\circ} \mathrm{S}$, with storm type designated by row and hail probability given by column. The average topography within this region is outlined in black.

storms captured by TRMM the diurnal cycle of convection can be inferred. For all high-hail-probability DCCs and DWCCs, storms begin to initiate around $1800 \mathrm{UTC}(1500 \mathrm{LT})$ between $55^{\circ}$ and $65^{\circ} \mathrm{W}$ in response to diurnal heating and upslope flow regimes (Figs. 5a,d). These storms then increase in frequency with time, but the favored locations do not move longitudinally, as was seen in similar Hovmöller analyses of lightning flash rates within DCCs from Rasmussen et al. (2014). WCCs occur later, with maximum frequency between 0000 and 0600 UTC, and are mostly located west of $60^{\circ} \mathrm{W}$ (Fig. $5 \mathrm{~g}$ ). There is little eastward propagation of these storms with time, until early in the morning after 0600 UTC.

For the medium-probability hailstorms, the diurnal cycle is shifted later (Figs. 5b,e), as shown earlier. The maximum frequency in the Hovmöller diagrams for all three types of extreme convection occurs after 0000 UTC (2100 LT). Medium-probability DCCs are clearly tied to the terrain near $65^{\circ} \mathrm{W}$, and they remain in place through 0600 UTC. WCCs tend to propagate eastward more than the other storm types, but they also do occur over the elevated terrain for a substantial amount of time (Fig. 5h), which concurs with previous research in this region (Rasmussen and Houze 2011, 2016; Rasmussen et al. 2014).

The null-convection cases do not seem to be specifically tied to the topography unlike the high- and medium-probability hail cases (Figs. 5c,f,i). There is increased frequency east of $60^{\circ} \mathrm{W}$ for all null-convection storm types and reduced frequency over the mountainous areas. Therefore, if a storm contains a medium to high probability of hail, it is more likely to be located near the Andes terrain and foothills relative to storms that do not. Additionally, the locations favoring both high and medium probability hailstorms tend to remain relatively stationary near the mountains and have secondary nocturnal peaks in frequency over these areas, which has been identified by previous research as well (Rasmussen and Houze 2011; Rasmussen et al. 2014). Thus, these new results support the notion that the Andes and SDC topography is a critical ingredient in 

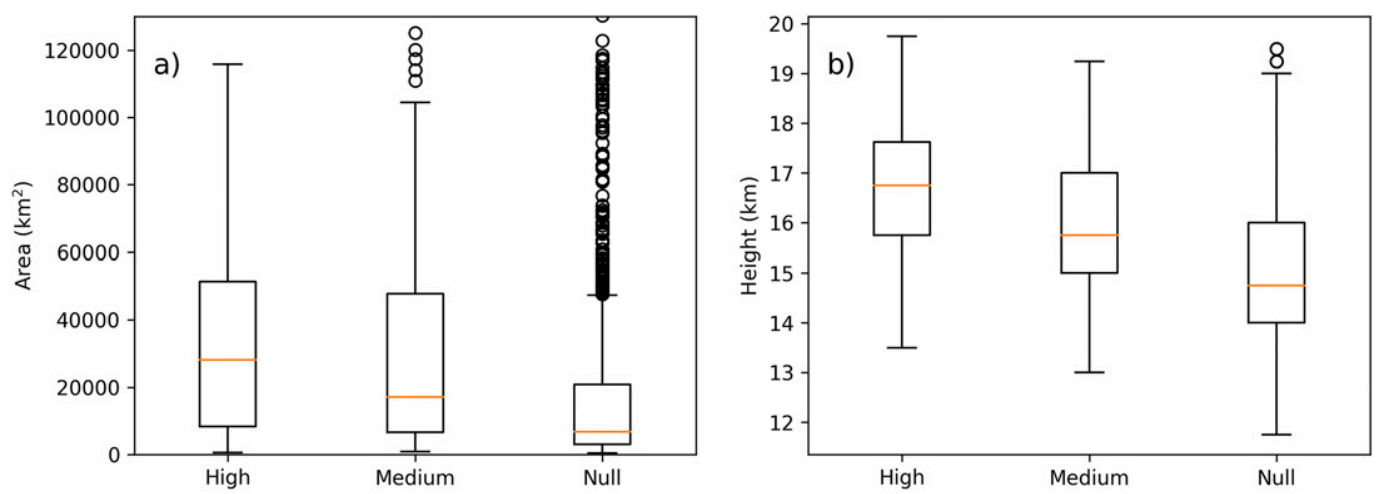

FIG. 6. Boxplots of storm (a) DCC area and (b) maximum height of the 40-dBZ echo core by hail threshold. The orange line represents the median, and the box spans the lower and upper quartiles of the data. The whiskers extend to 1.5 times the interquartile range, and any points outside that range are classified as outliers and labeled with open circles.

producing intense lightning- and hail-producing storms in the region.

\section{b. Hailstorm mode}

Using the same convective storm mode definitions applied to the TRMM-based methodology as in Mulholland et al. (2018), the high-probability hailstorms that occurred between September and March were classified as discrete, multicell organized, or multicell unorganized. A total of 264 high-probability storms were analyzed across all storm types with the following results: $6.8 \%$ of storms were discrete, $84.5 \%$ were multicell organized, and $8.7 \%$ were multicell unorganized. There is some potential bias because the $\sim 150-\mathrm{km}^{2}$ TRMM $37-\mathrm{GHz}$ footprint size may lead to underestimating the likelihood of hail from discrete cells, thereby preventing some discrete cells from qualifying as "high-probability" storms. However, the TRMM PR-based and ground-radar-based classification of discrete storms in Mulholland et al. (2018) came within $10 \%-15 \%$ of each other, indicating that the TRMM PR-based classification is a useful tool when ground-based radar data are unavailable. This study also found $80 \%$ of identified storms to be multicellular in nature as well. Therefore, the analysis contained here shows that a large majority of high-probability hailstorms during the austral spring and summer are multicellular and that they are usually organized. This is not simply because there were more DWCC and WCC storms included in this analysis, which naturally tend to be multicellular, as $83 \%$ of DCCs analyzed were also multicellular. While this classification method is unable to diagnose rotation within storms, which affects the growth of hailstones (Ashworth and Knight 1978), these findings indicate that a majority of significant hail production does not come from discrete storms, such as isolated supercells, but rather from organized multicell convection, such as mesoscale convective systems (MCSs). Additionally, of the 15 hailstorms with documented evidence of hail in Rasmussen et al. (2014), 7 of the storms were medium- or high-hail-probability DWCCs and 2 were medium- or high-hail-probability WCCs. These findings provide some ground truth that large, organized, multicellular convection does indeed produce severe hail.
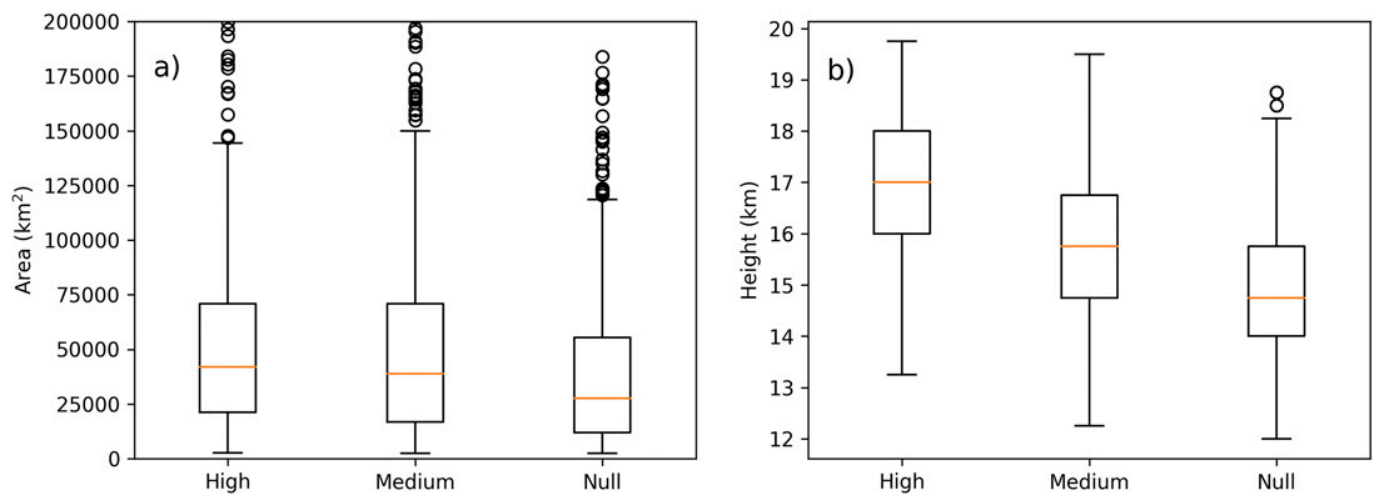

FIG. 7. As in Fig. 6, but for DWCCs. 

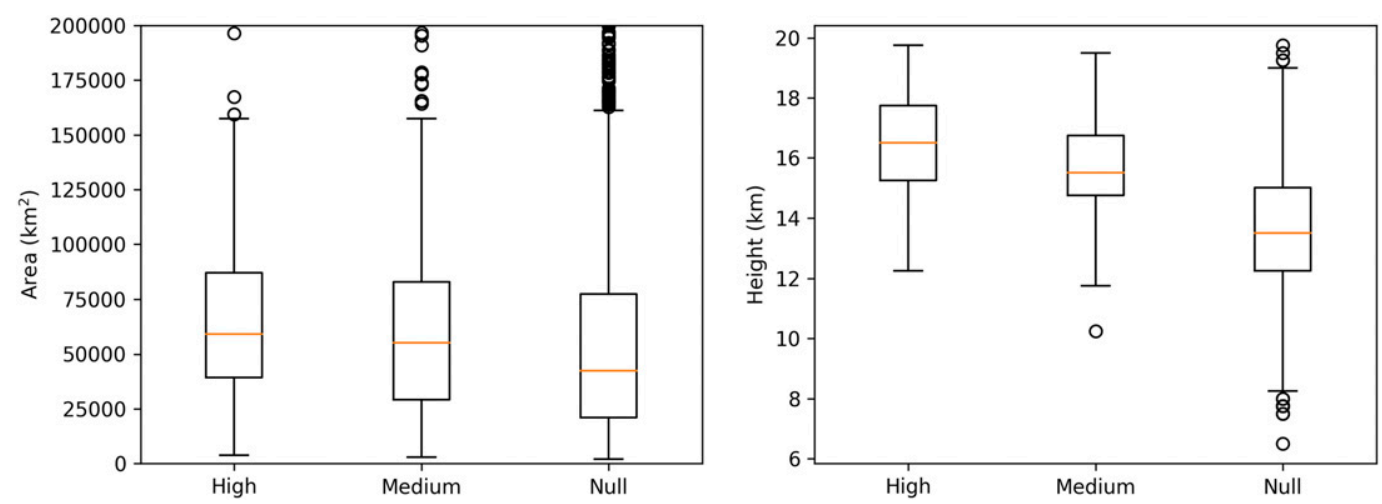

FIG. 8. As in Fig. 6, but for WCCs.

These results stand in contrast with the hailstorms in the United States, where a majority of hail has been found to come from discrete storms (Blair et al. 2011, 2017; Grams et al. 2012; Smith et al. 2012). Some research has shown that multicell-organized convection can produce all types of severe weather, including hail (Gallus et al. 2008). Hail is most likely to be produced by MCSs classified as leading stratiform or line parallel, because they can form in synoptic environments that are similar to those of supercell thunderstorms. However, observational studies in Canada (Marwitz 1972), Spain (Sánchez et al. 2003), and the United States (Kennedy and Detwiler 2003) have shown that multicellular storms do produce hail if environmental conditions are sufficiently favorable.

The satellite-based method used herein responds to the hail and graupel volume in the storm and does not provide sufficient information on the size distribution of hail within each storm. Due to the lack of systematic storm reports in this region, it is challenging to correlate radiometer-indicated hail with ground truth observations. It is certainly possible that the large hail $(>2 \mathrm{~cm})$ consistently reported by ground observations in subtropical South America still does occur within discrete or embedded supercells, but is beyond the scope of the current study given observational limitations. The satellite data are also better suited for highlighting horizontally extensive storms than smaller storms. However, it is also likely that given the results from this analysis, MCSs in this region are more likely to produce hail relative to their counterparts in the United States (as in Rasmussen et al. 2014). Overall, the results presented within this study suggest a significant difference in the hailstorm mode in subtropical South America that is not found in the United States.

\section{c. Hailstorm characteristics}

When a DCC more likely contains hail, per satellite measurements, it is also likely to be horizontally larger and vertically deeper than DCCs with less possibility of
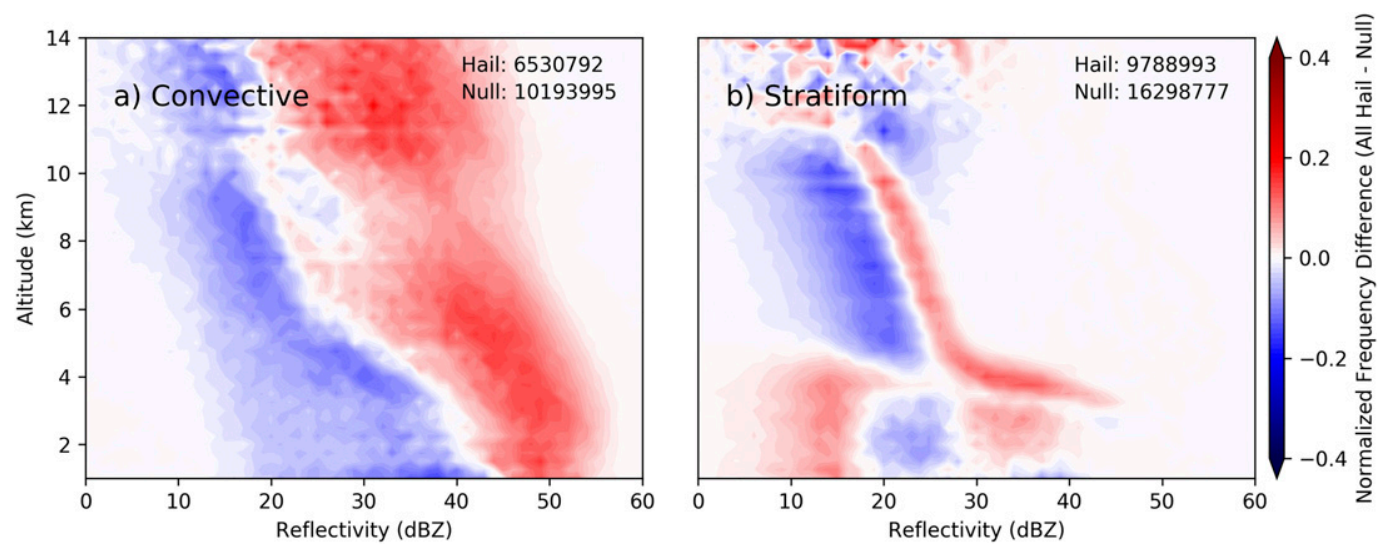

FIG. 9. Differenced CFAD (Yuter and Houze 1995) for DCCs, separated by (a) convective and (b) stratiform rain, with each vertical level normalized by the most frequent reflectivity bin within that level. Positive values represent an increase in frequency for storms with a nonzero hail probability. The number of pixels that went into each composite are listed in the top-right corner of (a) and (b). 

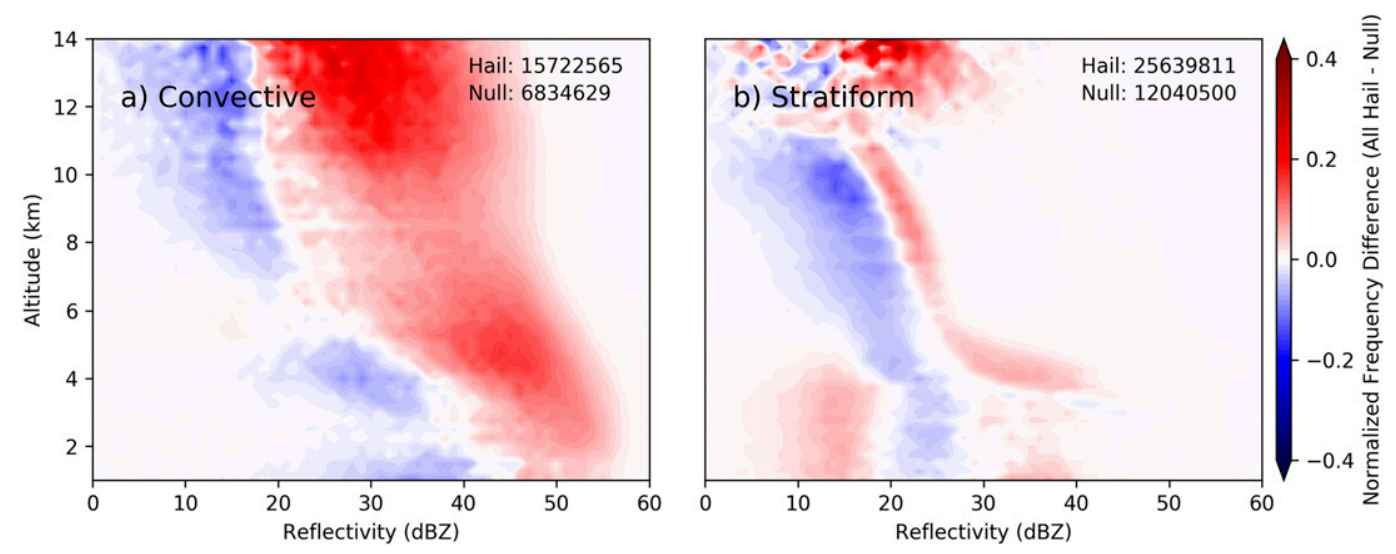

FIG. 10. As in Fig. 9, but for DWCCs.

containing hail (Fig. 6). DCCs with a high probability of hail have a greater average area by more than $21000 \mathrm{~km}^{2}$, whereas DCCs with medium hail probability have an increased area by about $16000 \mathrm{~km}^{2}$. Additionally, probable DCC hailstorms tend to be deeper, by $1-2 \mathrm{~km}$ on average, than DCC null cases. All of these differences in area and depth are significant at the $99 \%$ confidence interval. The result that deeper storms are more likely to contain hail is not a surprising one, because other recent studies using satellite-based radars have found similar results (Ni et al. 2016, 2017; Mroz et al. 2017). However, the larger horizontal area associated with hailstorms in subtropical South America is a result that is unique to this study and supports the results from section $3 \mathrm{~b}$ above.

When a DCC has begun to grow upscale, it is likely to reach the DWCC classification, as the spatial area of its convective core increases significantly. At this stage, though, it still maintains its deep component, representing persistent and strong updrafts. For DWCCs, probable hailstorms remain larger and deeper than null convection, with the difference significant at the $99 \%$ confidence interval (Fig. 7). The differences in area between high- and medium-probability hailstorms and null convection is smaller than the differences found with DCCs. Once these storms lose their DCCs and are solely WCCs, they tend to have similar height differences between probable hailstorms and null cases, but their areas are more similar, as upscale growth processes mature these systems into large storms regardless of their hail production chances (Fig. 8).

To further understand the structure of these hailproducing storms, TRMM PR reflectivity data was analyzed using contoured frequency-by-altitude diagrams (CFADs; Yuter and Houze 1995). At each vertical level, the frequencies are normalized by the maximum frequency at that level. For DCCs, there is a strong shift to higher reflectivities within the convective core for probable hailstorms, as compared with DCCs with less chance of hail production (Fig. 9a). Meanwhile, for stratiform rain, a complex tripole structure exists in which hailstorms have increases in high and low reflectivity values (Fig. 9b). There is low confidence in this signal because of the inability of the radar to measure intense rainfall below ice layers (Battaglia et al. 2016),
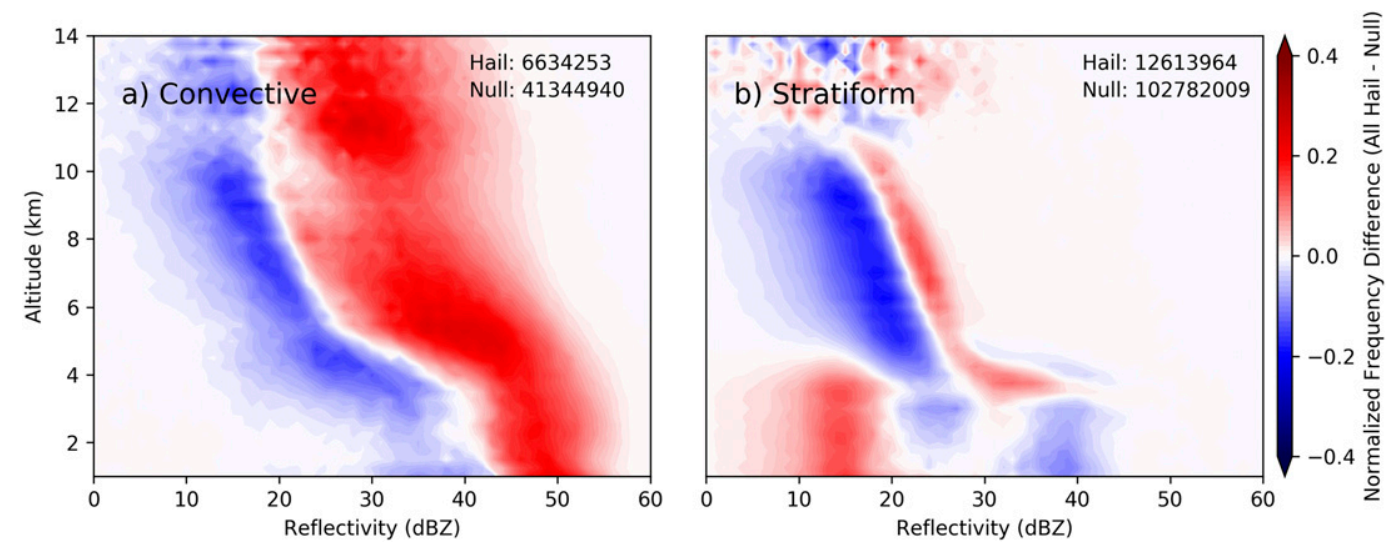

FIG. 11. As in Fig. 9, but for WCCs. 

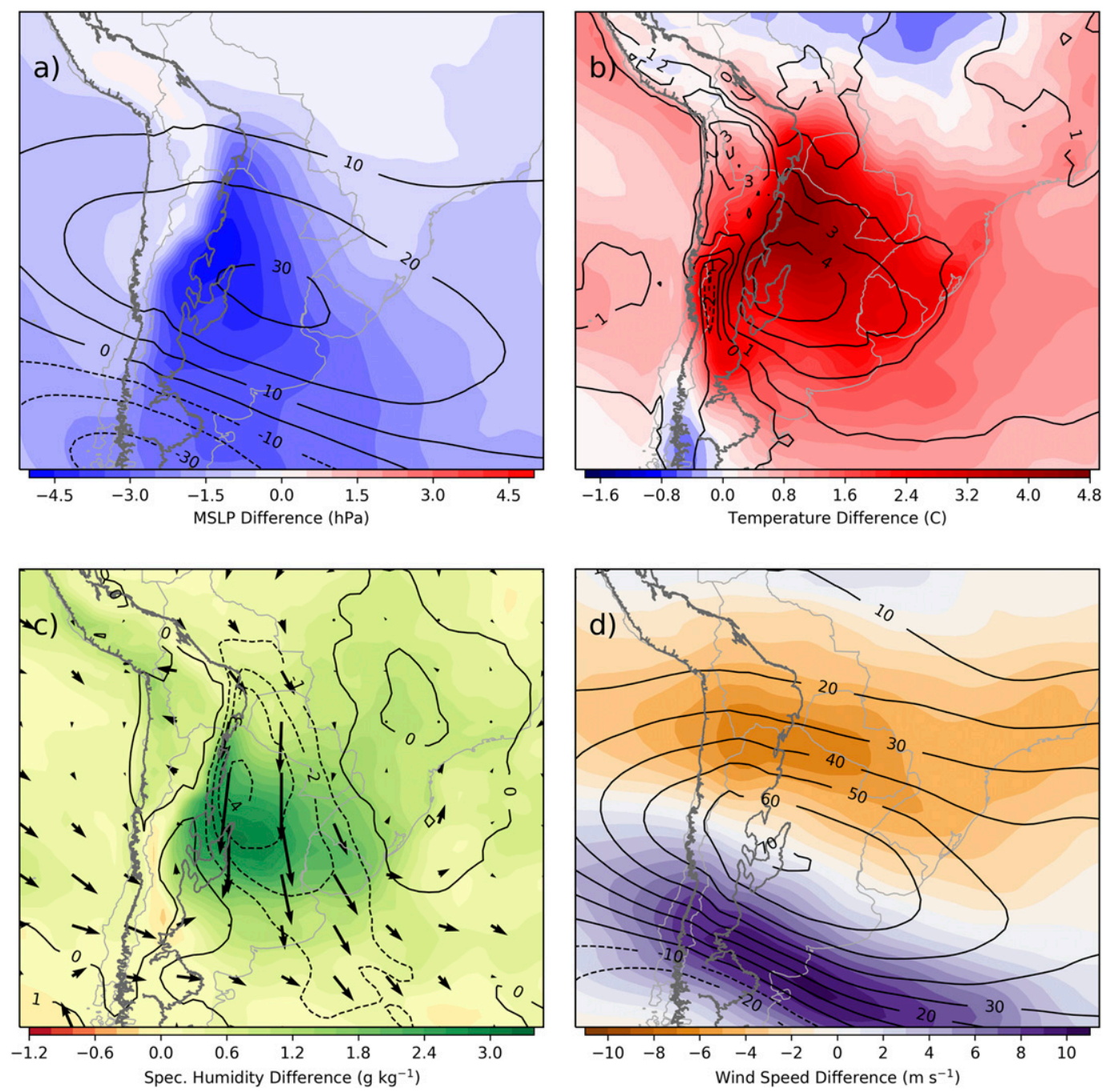

FIG. 12. The difference between high-probability hailstorm and nonhailstorm convective days is plotted for multiple vertical levels (convection had to occur within the primary study area in subtropical South America to be counted): differences in (a) mean sea level pressure (shaded) and geopotential height (contoured); (b) 2-m temperature (shaded) and 2-m dewpoint (contoured); (c) 850-hPa specific humidity (shaded), meridional wind speed (contoured), and wind (vectors); and (d) 250-hPa wind speed (shaded) and geopotential height (contoured).

which are undoubtedly present within these storms. Within DWCC storms, there is a greater frequency of higher reflectivities for convective rain if a storm has the likelihood of containing large hail (Fig. 10a). Additionally, a similar tripole signal exists for the DWCC stratiform reflectivity difference (Fig. 10b). When these storms reach the WCC stage of their life cycle, convective regions within hailstorms still have a strong shift to higher reflectivities than null convection (Fig. 11a). For all three storm types, the convective difference profile bends to higher reflectivities just below $4 \mathrm{~km}$ where the melting level resides. Even when hail is present somewhere within a storm, a large majority of the radar profiles will contain high-reflectivity liquid rain at low levels with lower-reflectivity ice aloft.

\section{d. Synoptic environments of hailstorms}

Understanding the environment in which these dangerous hailstorms form will provide better details to help forecasters warn the public ahead of such conditions. It is important to note that hail production is not simply a result of the environmental conditions in which storms form. Rather, internal storm dynamics play a significant role in hail production (e.g., Ashworth and Knight 1978; Nelson 1987; Grant and van den Heever 2014). However, the consideration of storm dynamics is outside 

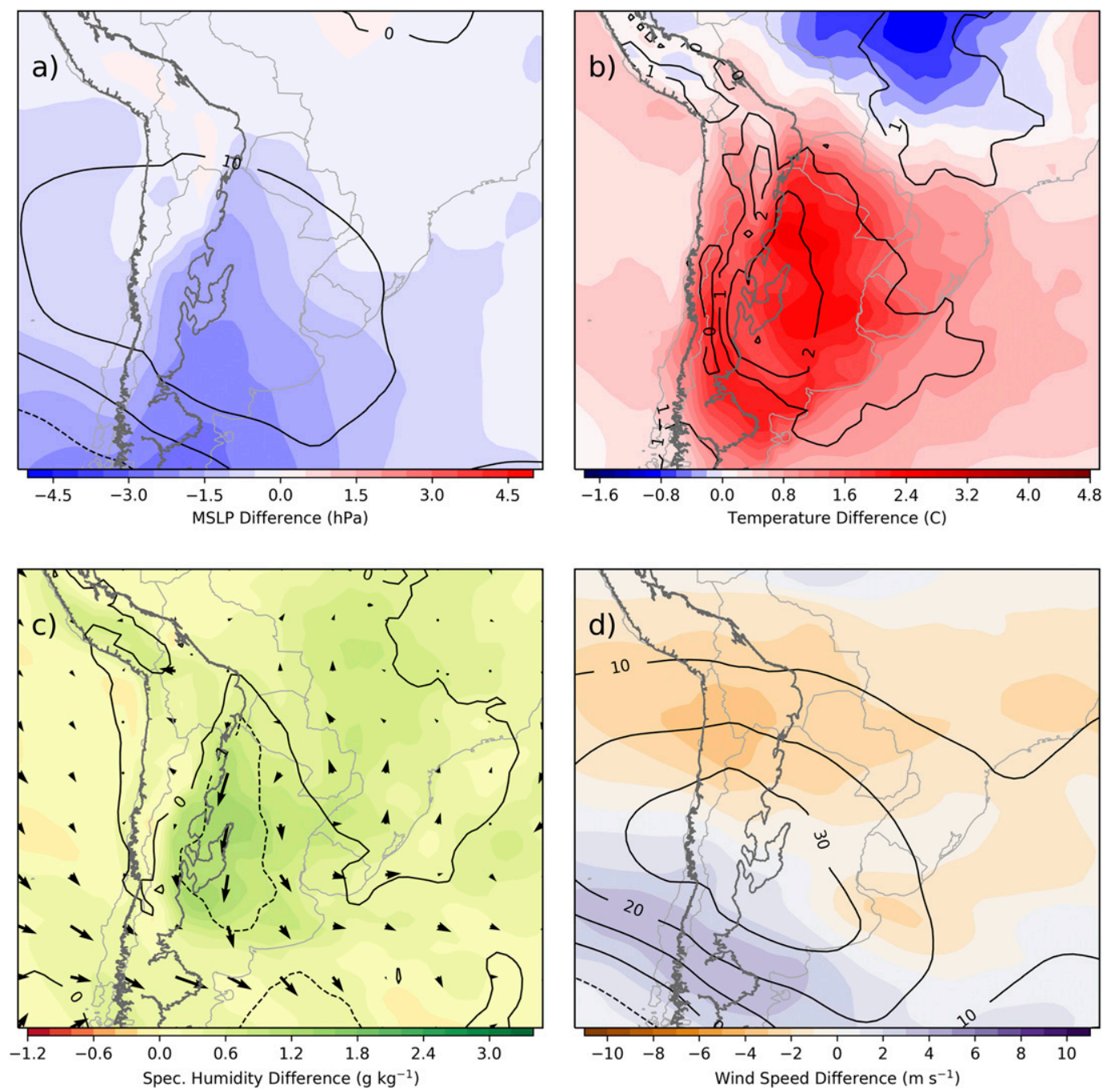

FIG. 13. As in Fig. 12, but showing the differences between medium-probability hail days and null-case convective days.

the scope of this study and may be considered in future work using RELAMPAGO and CACTI observations. This analysis contains 136, 187, and 1180 unique days for high-probability hailstorms, medium-probability hailstorms, and null-case storms, respectively. By examining the differences in synoptic environments between highprobability hailstorm days and null-case storm days, potentially useful signals for forecasting may be identified. At the surface (Fig. 12a), the lee cyclone has a negative mean sea level pressure anomaly centered just north of the SDC during hailstorm days as compared with null-case storm days. This corresponds to lee cyclone development that preceded intense convection identified by Rasmussen and Houze (2016). Additionally, the 2-m temperature and dewpoint temperature increases by about $4{ }^{\circ} \mathrm{C}$ along the foothills and northern SDC (Fig. 12b). Meanwhile, at the $850-\mathrm{hPa}$ pressure level, specific humidity is increased during hailstorm days to the east of the SDC upward of $3 \mathrm{~g} \mathrm{~kg}^{-1}$ (Fig. 12c). The SALLJ is also strengthened, with northerly wind speeds increased by $4 \mathrm{~m} \mathrm{~s}^{-1}$ over northern Argentina, similar to findings from Rasmussen and Houze (2016). In the upper troposphere, a trough is moving onshore over southern South America, with ridging downstream (Figs. 12a,d). As a result of this anomalous height pattern, the upper-level jet stream is shifted south and the wind speed enhanced by $10 \mathrm{~m} \mathrm{~s}^{-1}$. This southward shift of the jet stream places the equatorward entrance region of the jet over the SDC and foothills in central Argentina, which enables rising motion to help break any capping inversion that may exist in addition to orographic lifting.

If the same method is applied to the mediumprobability hailstorm cases, similar qualitative anomalies are identified at all vertical levels (Fig. 13). However, the 

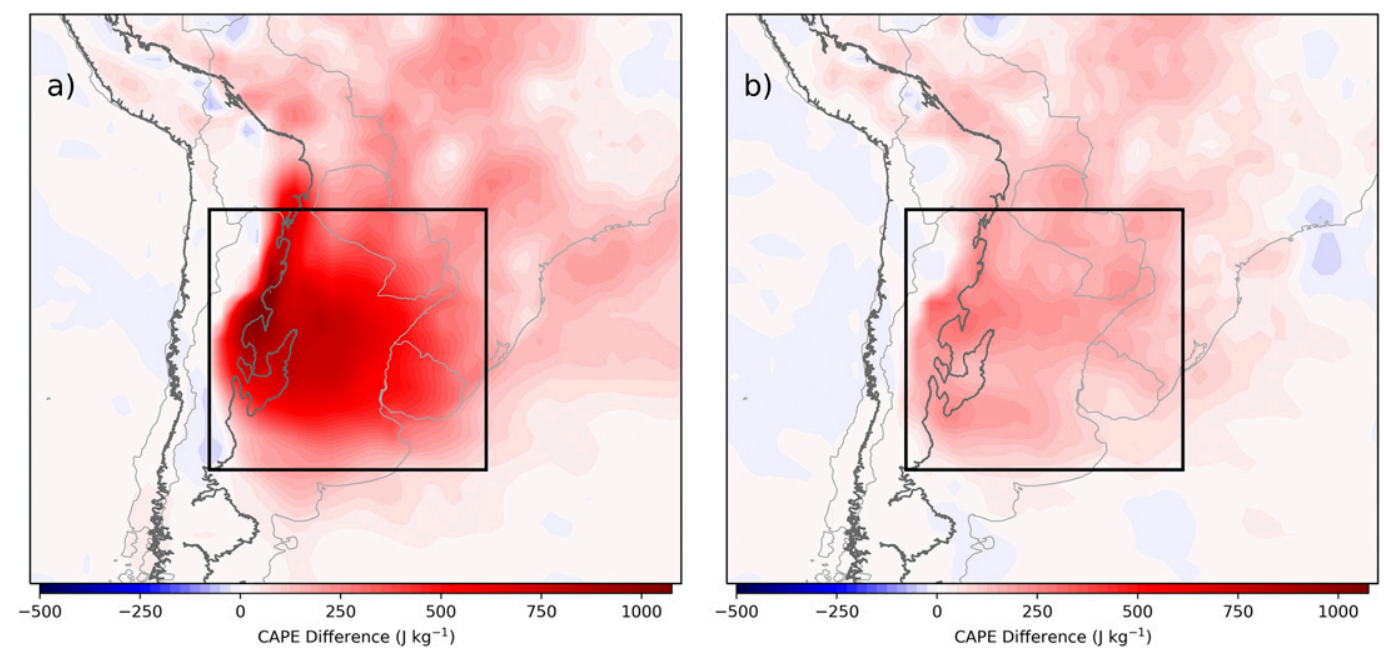

FIG. 14. The difference in surface-based CAPE between (a) upper-threshold hail days and null-case convective days and (b) lower-threshold hail days and null-case convective days.

magnitude of these anomalies is reduced by approximately $50 \%$, as the magnitude of the synoptic anomalies is correlated with the probability of hail. As a result, these synoptic anomalies for hailstorm days seem to be useful from a forecasting perspective. The low-level temperature and moisture anomalies should affect the available instability for these storms as well. Indeed, convective available potential energy (CAPE) is increased across much of the study region by an average of $600-900 \mathrm{~J} \mathrm{~kg}^{-1}$ during high-probability hailstorm days and $200-300 \mathrm{~J} \mathrm{~kg}^{-1}$ on medium-probability hailstorm days, as compared with null-convection days (Fig. 14). When the maximum CAPE within the study region is compared between the hail probability and null categories, there is also a clear distinction between days that contained storms with much likelihood of hail as compared to days with null storm cases, even though they still contained convection (Fig. 15). The mean maximum CAPE values for high-probability, medium-probability, and null hailstorm days are 3439,2835 , and $2416 \mathrm{~J} \mathrm{~kg}^{-1}$, respectively. The difference between these means is statistically significant at the $99 \%$ confidence interval. By enhancing instability, stronger updrafts are able to form, which would be more capable of supporting large hail. Of course, updraft strength is not only a product of thermodynamic instability, but is also affected by dynamic contributions such as storm rotation (e.g., Dennis and Kumjian 2017), as well as hydrometeor loading and entrainment. However, deep vertical wind shear was evaluated and there were no significant differences between the hail categories, with very similar means overall (Table 2).

Last, the SALLJ has been theorized to play a main role in the initiation, maintenance, and backbuilding of convection near the Sierras de Córdoba (e.g., Rasmussen and Houze 2011, 2016). While the 1800 UTC anomalies were shown earlier in Figs. 12 and 13, the 0000 and 0600 UTC SALLJ anomalies are included in Fig. 16. For the high-probability hail days, the SALLJ remains anomalously strong, as it continues to advect moisture into the region and provide orographic forcing for ascent. Romatschke and Houze (2010) found a similar diurnal cycle of the SALLJ for the intense convective cases they analyzed. The medium-probability days have more modest increases in the strength of the SALLJ, with minimal increases in wind speed or specific humidity. Additionally, the SALLJ does not appear to rotate very much with time as is seen in the United States (Shapiro et al. 2016). In general, it does seem that the SALLJ is important for strong convective storms in this region, especially for those that produce hail.

Overall, these hailstorms appear to be more strongly forced by the synoptic environment relative to the

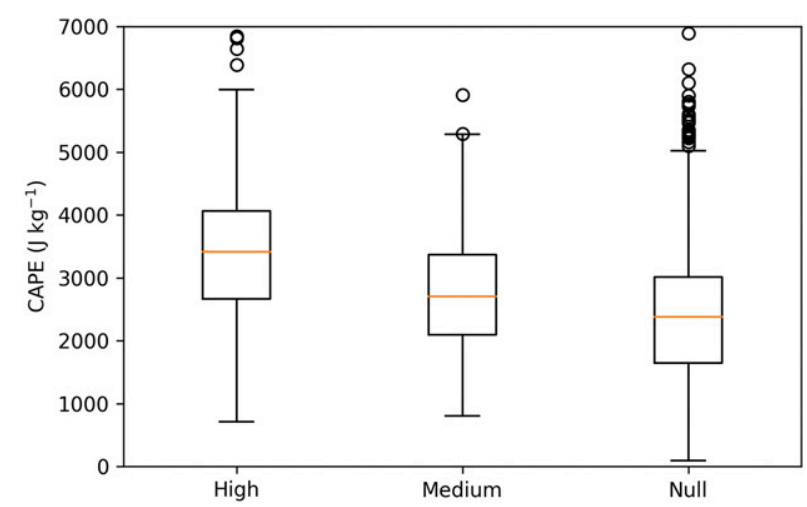

FIG. 15. Boxplots of the maximum CAPE found within the study region based upon the maximum hail probability found within the region on a particular day. 
TABLE 2. The mean and standard deviation of the surface-500-hPa vertical wind shear (VWS) hail-probability category.

\begin{tabular}{lcc}
\hline & VWS mean $\left(\mathrm{m} \mathrm{s}^{-1}\right)$ & VWS std dev $\left(\mathrm{m} \mathrm{s}^{-1}\right)$ \\
\hline High probability & 14.44 & 3.95 \\
Medium probability & 14.22 & 4.45 \\
Null probability & 14.88 & 4.77 \\
\hline
\end{tabular}

null-convection category. The ingredients for vigorous deep convection are more easily produced by strong synoptic forcing, such as when a trough is moving into the region, bringing colder upper-level air, a strong jet stream, and a low-level jet that imports abundant moisture. Through these enhanced synoptic conditions, hailstorms can more easily form in this region, often with very large hail. These results do not preclude hailstorm formation within weakly forced environments, but rather they show the tendency to have these strong storms occur in strongly forced synoptic conditions.

\section{Conclusions}

Convection in subtropical South America is known to be some of the most intense anywhere on Earth. As a result, understanding the severe convective hazards produced by storms within this region is critical, as they threaten personal safety, agriculture, and socioeconomic considerations in Argentina. Within this region, hail is notably frequent in occurrence compared to other regions of the world, but little work has been done to
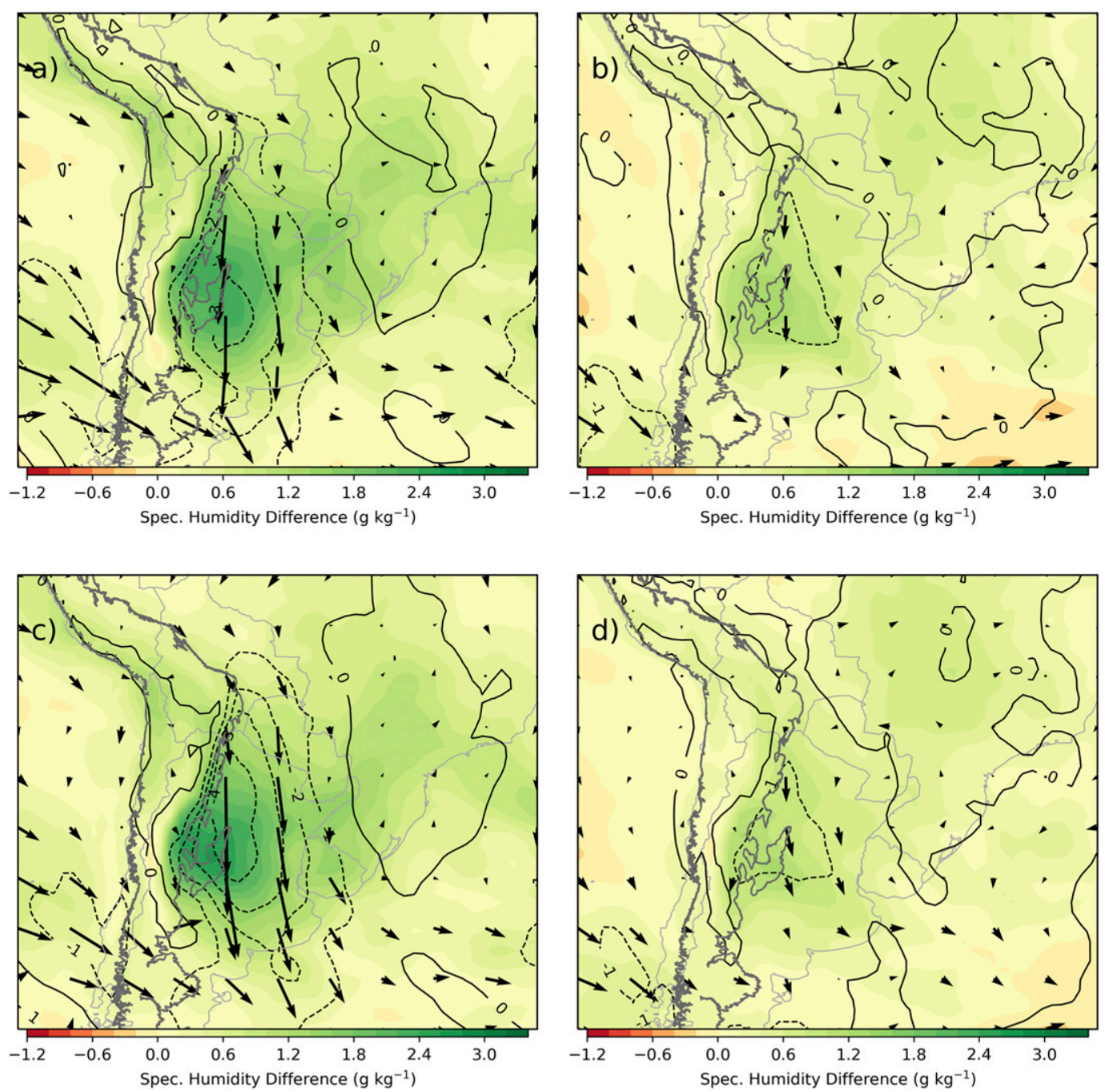

FIG. 16. The differences in 850 -hPa specific humidity (shaded), meridional wind speed (contoured), and wind (vectors) at (a),(b) 0000 and (c),(d) 0600 UTC between (left) high-probability and null-case hail days and between (right) medium-probability and null-case hail days. 
understand hailstorm characteristics, structure, or supporting environments. This study aims to provide insight into this important problem by utilizing long-term satellite measurements of intense convection to identify hailstorm characteristics and their supporting environments to provide a greater understanding of high-impact weather around the world.

Hailstorms are found to have an annual cycle similar to the United States, with the maximum hailstorm activity occurring during the spring and summer. However, per these satellite-based methods, hailstorms in subtropical South America have an extended diurnal cycle, compared to that found in the United States, with a substantial portion of the distribution occurring during the overnight period. If a sufficient database of hail reports from subtropical South America is organized in the future, it would be beneficial to compare the diurnal cycle and other statistics from such a source to the U.S. hail reports, in order to add ground truth to these satellite-based findings. Additionally, a large majority $(\sim 84 \%)$ of these storms were found to be organized multicellular convection. Both the diurnal cycle and storm mode of hailstorms in subtropical South America are notably different from hailstorms in the United States that are primarily discrete storms that occur in the late afternoon hours. Hailstorms in this region also tend to be deeper and larger in horizontal area than storms that do not contain hail. Finally, hailstorms are supported by enhanced synoptic conditions, including increased instability through low-level temperature and moisture increases, an enhanced lee trough and SALLJ, and stronger upper-level jet streams.

While hailstorms in subtropical South America are supported synoptically by similar conditions to those found in the United States, the storm mode and diurnal cycles of these storms are very different. As a result, they prove to be a challenge to forecast from numerical and operational perspectives, as the knowledge gained by studying U.S. hailstorms does not apply to this region as well as might be expected. Therefore, the results of the RELAMPAGO and CACTI field campaigns will be critical in improving the understanding of hailstorms within this region. Additionally, new understanding about hailstorms characteristics and associated environmental conditions in subtropical South America may aid the comprehension of hailstorms in the United States and other regions of the world, which in turn will improve forecasting of these dangerous storms. Future work will make use of the observations from this campaign to better understand why the diurnal cycle of hailstorms extends into the overnight hours, in addition to the analysis of rotation within storms and its role in supporting hailstone growth in a variety of convective modes.
Acknowledgments. The authors thank three anonymous reviewers for their insightful comments and suggestions, which greatly improved this manuscript. This research was sponsored by National Science Foundation Grant AGS-1661657 and an American Meteorological Society/NASA Earth Science graduate fellowship.

\section{REFERENCES}

Allen, J. T., and M. K. Tippett, 2015: The characteristics of United States hail reports: 1955-2014. Electron. J. Severe Storms Meteor., 10 (3), http://www.ejssm.org/ojs/index.php/ ejssm/article/viewArticle/149.

Arias, C., and E. Ramiro, 2010: Recopilación histórica y análisis climatológico de eventos de granizada ocurridos sobre Bogotá y su relación con el cambio climático global/Historical data collection and climatological analysis of hailstorms events occurring over Bogota and its relation to global climate change. Universidad Nacional de Colombia Rep., 342 pp., http:// bdigital.unal.edu.co/3776.

Ashworth, T., and C. A. Knight, 1978: Cylindrical ice accretions as simulations of hail growth: I. Effects of rotation and of mixed clouds. J. Atmos. Sci., 35, 1987-1996, https://doi.org/10.1175/ 1520-0469(1978)035<1987:CIAASO >2.0.CO;2.

Awaka, J., T. Iguchi, H. Kumagai, and K. Okamoto, 1997: Rain type classification algorithm for TRMM precipitation radar. 1997 IEEE Int. Geoscience and Remote Sensing Symp., Singapore, IEEE, 1633-1635, https://doi.org/10.1109/IGARSS.1997.608993.

Bang, S. D., and D. J. Cecil, 2019: Constructing a multifrequency passive microwave hail retrieval and climatology in the GPM domain. J. Appl. Meteor. Climatol., 58, 1889-1904, https:// doi.org/10.1175/JAMC-D-19-0042.1.

Battaglia, A., K. Mroz, S. Tanelli, F. Tridon, and P.-E. Kirstetter, 2016: Multiple-scattering-induced "ghost echoes" in GPM DPR observations of a tornadic supercell. J. Appl. Meteor. Climatol., 55, 1653-1666, https://doi.org/10.1175/JAMC-D-150136.1.

Bedka, K. M., J. T. Allen, H. J. Punge, M. Kunz, and D. Simanovic, 2018: A long-term overshooting convective cloud-top detection database over Australia derived from MTSAT Japanese Advanced Meteorological Imager Observations. J. Appl. Meteor. Climatol., 57, 937-951, https://doi.org/10.1175/ JAMC-D-17-0056.1.

Blair, S. F., D. R. Deroche, J. M. Boustead, J. W. Leighton, B. L. Barjenbruch, and W. P. Gargan, 2011: A radar-based assessment of the detectability of giant hail. E-J. Severe Storms Meteor., 6 (7), http://www.ejssm.org/ojs/index.php/ejssm/article/ viewArticle/87.

_ _ and Coauthors, 2017: High-resolution hail observations: Implications for NWS warning operations. Wea. Forecasting, 32, 1101-1119, https://doi.org/10.1175/WAF-D-16-0203.1.

Cecil, D. J., 2009: Passive microwave brightness temperatures as proxies for hailstorms. J. Appl. Meteor. Climatol., 48, 1281-1286, https://doi.org/10.1175/2009JAMC2125.1.

_ , and C. B. Blankenship, 2012: Toward a global climatology of severe hailstorms as estimated by satellite passive microwave imagers. J. Climate, 25, 687-703, https://doi.org/10.1175/JCLID-11-00130.1.

- and T. Chronis, 2018: Polarization corrected temperatures for 10-, 19-, 37-, and 89-GHz passive microwave frequencies. J. Appl. Meteor. Climatol., 57, 2249-2265, https://doi.org/ 10.1175/JAMC-D-18-0022.1 
Cintineo, J. L., T. M. Smith, V. Lakshmanan, H. E. Brooks, and K. L. Ortega, 2012: An objective high-resolution hail climatology of the contiguous United States. Wea. Forecasting, 27, 1235-1248, https://doi.org/10.1175/WAF-D-11-00151.1.

Dee, D. P., and Coauthors, 2011: The ERA-Interim reanalysis: Configuration and performance of the data assimilation system. Quart. J. Roy. Meteor. Soc., 137, 553-597, https://doi.org/10.1002/qj.828.

Dennis, E. J., and M. R. Kumjian, 2017: The impact of vertical wind shear on hail growth in simulated supercells. J. Atmos. Sci., 74, 641-663, https://doi.org/10.1175/JAS-D-16-0066.1.

Etkin, D., and S. E. Brun, 2001: Canada's hail climatology: 1977-1993. Institute for Catastrophic Loss Reduction Paper Series No. 14, 14 pp., https://pdfs.semanticscholar.org/ 8532/b05945d8c455e87f4c9c920e89aa2457e028.pdf.

Ferraro, R., J. Beauchamp, D. Cecil, and G. Heymsfield, 2015: A prototype hail detection algorithm and hail climatology developed with the Advanced Microwave Sounding Unit (AMSU). Atmos. Res., 163, 24-35, https://doi.org/10.1016/ j.atmosres.2014.08.010.

Frisby, E. M., and H. W. Sansom, 1967: Hail incidence in the tropics. J. Appl. Meteor., 6, 339-354, https://doi.org/10.1175/ 1520-0450(1967)006<0339:HIITT>2.0.CO;2.

Gallus, W. A., N. A. Snook, and E. V. Johnson, 2008: Spring and summer severe weather reports over the Midwest as a function of convective mode: A preliminary study. Wea. Forecasting, 23, 101-113, https://doi.org/10.1175/2007WAF2006120.1.

Grams, J. S., R. L. Thompson, D. V. Snively, J. A. Prentice, G. M. Hodges, and L. J. Reames, 2012: A climatology and comparison of parameters for significant tornado events in the United States. Wea. Forecasting, 27, 106-123, https://doi.org/10.1175/ WAF-D-11-00008.1.

Grandoso, H. N., and J. V. Iribarne, 1963: Evaluation of the first three years in a hail prevention experiment in Mendoza (Argentina). Z. Angew. Math. Phys., 14, 549-553, https:// doi.org/10.1007/BF01601262.

Grant, L. D., and S. C. van den Heever, 2014: Microphysical and dynamical characteristics of low-precipitation and classic supercells. J. Atmos. Sci., 71, 2604-2624, https://doi.org/10.1175/ JAS-D-13-0261.1.

Haberlie, A. M., and W. S. Ashley, 2019: A radar-based climatology of mesoscale convective systems in the United States. J. Climate, 32, 1591-1606, https://doi.org/10.1175/JCLI-D-18-0559.1.

Houze, R. A., Jr., 2004: Mesoscale convective systems. Rev. Geophys., 42, RG4003, https://doi.org/10.1029/2004RG000150.

_ D. C. Wilton, and B. F. Smull, 2007: Monsoon convection in the Himalayan region as seen by the TRMM Precipitation Radar. Quart. J. Roy. Meteor. Soc., 133, 1389-1411, https:// doi.org/10.1002/qj.106.

—, K. L. Rasmussen, M. D. Zuluaga, and S. R. Brodzik, 2015: The variable nature of convection in the tropics and subtropics: A legacy of 16 years of the Tropical Rainfall Measuring Mission satellite. Rev. Geophys., 53, 994-1021, https:// doi.org/10.1002/2015RG000488.

Iguchi, T., T. Kozu, R. Meneghini, J. Awaka, and K. Okamoto, 2000: Rain-profiling algorithm for the TRMM Precipitation Radar. J. Appl. Meteor., 39, 2038-2052, https://doi.org/10.1175/ 1520-0450(2001)040<2038:RPAFTT>2.0.CO;2.

Kennedy, P. C., and A. G. Detwiler, 2003: A case study of the origin of hail in a multicell thunderstorm using in situ aircraft and polarimetric radar data. J. Appl. Meteor., 42, 1679-1690, https:// doi.org/10.1175/1520-0450(2003)042<1679:ACSOTO>2.0.CO;2.

Kummerow, C., W. Barnes, T. Kozu, J. Shiue, and J. Simpson, 1998: The Tropical Rainfall Measuring Mission (TRMM) sensor package. J. Atmos. Oceanic Technol., 15, 809-817, https://doi.org/ 10.1175/1520-0426(1998)015<0809:TTRMMT>2.0.CO;2.

, and Coauthors, 2000: The status of the Tropical Rainfall Measuring Mission (TRMM) after two years in orbit. J. Appl. Meteor., 39, 1965-1982, https://doi.org/10.1175/1520-0450(2001) 040<1965:TSOTTR $>2.0 . \mathrm{CO} ; 2$.

Li, X., Q. Zhang, T. Zou, J. Lin, H. Kong, and Z. Ren, 2018: Climatology of hail frequency and size in China, 1980-2015. J. Appl. Meteor. Climatol., 57, 875-887, https://doi.org/ 10.1175/JAMC-D-17-0208.1.

Makitov, V., 1999: Organization and main results of the hail suppression program in the northern area of the Province of Mendoza, Argentina. J. Wea. Modif., 31, 76-86, http:// journalofweathermodification.org/index.php/JWM/article/ view/250.

Martins, J. A., and Coauthors, 2017: Climatology of destructive hailstorms in Brazil. Atmos. Res., 184, 126-138, https://doi.org/ 10.1016/j.atmosres.2016.10.012.

Marwitz, J. D., 1972: The structure and motion of severe hailstorms. Part II: Multi-cell storms. J. Appl. Meteor., 11, 180-188, https://doi.org/10.1175/1520-0450(1972)011<0180:TSAMOS> 2.0.CO;2.

Matsudo, C. M., and P. V. Salio, 2011: Severe weather reports and proximity to deep convection over Northern Argentina. Atmos. Res., 100, 523-537, https://doi.org/10.1016/j.atmosres.2010.11.004.

Mezher, R. N., M. Doyle, and V. Barros, 2012: Climatology of hail in Argentina. Atmos. Res., 114-115, 70-82, https://doi.org/ 10.1016/j.atmosres.2012.05.020.

Mroz, K., A. Battaglia, T. J. Lang, D. J. Cecil, S. Tanelli, and F. Tridon, 2017: Hail-detection algorithm for the GPM Core Observatory satellite sensors. J. Appl. Meteor. Climatol., 56, 1939-1957, https://doi.org/10.1175/JAMC-D-16-0368.1.

Mulholland, J. P., S. W. Nesbitt, R. J. Trapp, K. L. Rasmussen, and P. V. Salio, 2018: Convective storm life cycle and environments near the Sierras de Córdoba, Argentina. Mon. Wea. Rev., 146, 2541-2557, https://doi.org/10.1175/MWR-D-18-0081.1.

Nelson, S. P., 1987: The hybrid multicellular-supercellular storm-An efficient hail producer. Part II. General characteristics and implications for hail growth. J. Atmos. Sci., 44, 2060-2073, https:// doi.org/10.1175/1520-0469(1987)044<2060:THMSEH>2.0.CO;2.

Ni, X., C. Liu, Q. Zhang, and D. J. Cecil, 2016: Properties of hail storms over China and the United States from the Tropical Rainfall Measuring Mission. J. Geophys. Res. Atmos., 121, 12 031-12 044, https://doi.org/10.1002/2016JD025600.

- _ _ D. J. Cecil, and Q. Zhang, 2017: On the detection of hail using satellite passive microwave radiometers and precipitation radar. J. Appl. Meteor. Climatol., 56, 2693-2709, https:// doi.org/10.1175/JAMC-D-17-0065.1.

Pérez, R. C., and E. Puliafito, 2006: Study of hailstorms cells producing big damages in Mendoza (Argentina). Proc. Fourth European Conf. on Radar in Meteorology and Hydrology, Barcelona, Spain, ERAD, 4 pp., http://www.crahi.upc.edu/ ERAD2006/proceedingsMask/00136.pdf.

Piersante, J., 2017: Characteristics of hail events near the Sierras de Córdoba, Argentina. SOARS Paper, 20 pp., https:// opensky.ucar.edu/islandora/object/manuscripts \%3A955/ datastream/PDF/view .

Počakal, D., Ž. Večenaj, and J. Štalec, 2009: Hail characteristics of different regions in continental part of Croatia based on influence of orography. Atmos. Res., 93, 516-525, https://doi.org/ 10.1016/j.atmosres.2008.10.017.

Prieto, R., L. Gimeno, R. García, R. Herrera, E. Hernández, and P. Ribera, 1999: Interannual variability of hail-days in the 
Andes region since 1885. Earth Planet. Sci. Lett., 171, 503-509, https://doi.org/10.1016/S0012-821X(99)00170-3.

Punge, H. J., K. M. Bedka, M. Kunz, and A. Reinbold, 2017: Hail frequency estimation across Europe based on a combination of overshooting top detections and the ERA-INTERIM reanalysis. Atmos. Res., 198, 34-43, https://doi.org/10.1016/ j.atmosres.2017.07.025.

Rasmussen, K. L., and R. A. Houze Jr., 2011: Orogenic convection in subtropical South America as seen by the TRMM satellite. Mon. Wea. Rev., 139, 2399-2420, https://doi.org/10.1175/MWRD-10-05006.1.

—, and - 2016: Convective initiation near the Andes in subtropical South America. Mon. Wea. Rev., 144, 2351-2374, https://doi.org/10.1175/MWR-D-15-0058.1.

—, M. D. Zuluaga, and R. A. Houze Jr., 2014: Severe convection and lightning in subtropical South America. Geophys. Res. Lett., 41, 7359-7366, https://doi.org/10.1002/2014GL061767.

—, M. M. Chaplin, M. D. Zuluaga, and R. A. Houze Jr., 2016: Contribution of extreme convective storms to rainfall in South America. J. Hydrometeor., 17, 353-367, https://doi.org/10.1175/ JHM-D-15-0067.1.

Romatschke, U., and R. A. Houze Jr., 2010: Extreme summer convection in South America. J. Climate, 23, 3761-3791, https:// doi.org/10.1175/2010JCLI3465.1.

$\longrightarrow$, and — 2011: Characteristics of precipitating convective systems in the South Asian monsoon. J. Hydrometeor., 12, 3-26, https://doi.org/10.1175/2010JHM1289.1.

Sánchez, J. L., M. V. Fernández, J. T. Fernández, E. Tuduri, and C. Ramis, 2003: Analysis of mesoscale convective systems with hail precipitation. Atmos. Res., 67-68, 573-588, https://doi.org/ 10.1016/S0169-8095(03)00074-7.

, and Coauthors, 2009: Characterization of hailstone size spectra in hailpad networks in France, Spain, and Argentina. Atmos. Res., 93, 641-654, https://doi.org/10.1016/j.atmosres.2008.09.033.
Shapiro, A., E. Fedorovich, and S. Rahimi, 2016: A unified theory for the Great Plains nocturnal low-level jet. J. Atmos. Sci., 73, 3037-3057, https://doi.org/10.1175/JASD-15-0307.1.

Smith, B. T., R. L. Thompson, J. S. Grams, C. Broyles, and H. E. Brooks, 2012: Convective modes for significant severe thunderstorms in the contiguous United States. Part I: Storm classification and climatology. Wea. Forecasting, 27, 1114-1135, https://doi.org/10.1175/WAF-D-11-00115.1.

Smith, S. B., and M. K. Yau, 1993: The causes of severe convective outbreaks in Alberta. Part II: Conceptual model and statistical analysis. Mon. Wea. Rev., 121, 1126-1133, https://doi.org/10.1175/1520-0493(1993)121<1126:TCOSCO > 2.0.CO;2.

Williams, L., 1973: Hail and its distribution. Engineer Topographic Laboratories Studies of the Army Aviation V/STOL Environment Rep. 8, 16 pp.

Yuter, S. E., and R. A. Houze, 1995: Three-dimensional kinematic and microphysical evolution of Florida cumulonimbus. Part II: Frequency distributions of vertical velocity, reflectivity, and differential reflectivity. Mon. Wea. Rev., 123, 1941-1963, https://doi.org/10.1175/1520-0493(1995)123<1941:TDKAME> 2.0.CO;2.

Zhang, C., Q. Zhang, and Y. Wang, 2008: Climatology of hail in China: 1961-2005. J. Appl. Meteor. Climatol., 47, 795-804, https://doi.org/10.1175/2007JAMC1603.1.

Zipser, E. J., D. J. Cecil, C. Liu, S. W. Nesbitt, and D. P. Yorty, 2006: Where are the most intense thunderstorms on earth? Bull. Amer. Meteor. Soc., 87, 1057-1072, https://doi.org/10.1175/ BAMS-87-8-1057.

Zuluaga, M. D., and R. A. Houze, 2015: Extreme convection of the near-equatorial Americas, Africa, and adjoining oceans as seen by TRMM. Mon. Wea. Rev., 143, 298-316, https://doi.org/ 10.1175/MWR-D-14-00109.1. 